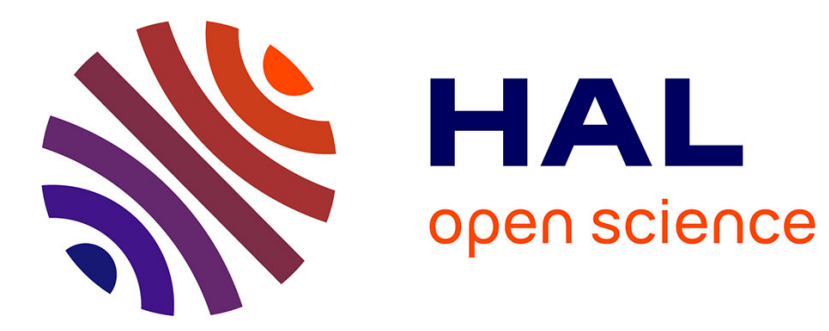

\title{
Power Management for a DC MicroGrid in a Smart Railway Station including Recovery Braking
}

\author{
Zeqin Sheng, Alessio Iovine, Gilney Damm, Lilia Galai-Dol
}

\section{To cite this version:}

Zeqin Sheng, Alessio Iovine, Gilney Damm, Lilia Galai-Dol. Power Management for a DC MicroGrid in a Smart Railway Station including Recovery Braking. 18th European Control Conference (ECC 2019), Jun 2019, Naples, Italy. pp.1418-1423, 10.23919/ECC.2019.8795676 hal-02290735

\section{HAL Id: hal-02290735 \\ https://hal.science/hal-02290735}

Submitted on 31 Mar 2021

HAL is a multi-disciplinary open access archive for the deposit and dissemination of scientific research documents, whether they are published or not. The documents may come from teaching and research institutions in France or abroad, or from public or private research centers.
L'archive ouverte pluridisciplinaire HAL, est destinée au dépôt et à la diffusion de documents scientifiques de niveau recherche, publiés ou non, émanant des établissements d'enseignement et de recherche français ou étrangers, des laboratoires publics ou privés. 


\title{
Power Management for a DC MicroGrid in a Smart Railway Station including Recovery Braking
}

\author{
Zeqin Sheng, Alessio Iovine, Member, IEEE, Gilney Damm, Member, IEEE, Lilia Galai-Dol
}

\begin{abstract}
A power management controller able to provide optimal reference values to local controllers for a DC microgrid recycling the train braking energy in a railway station is introduced. Power balance and desired energy levels are the targets of the proposed controller. Constraints regarding the nature of the devices or the physics of the grid are considered. Simulation results illustrating two different cases with their respective optimal control actions are provided.

Index terms - Microgrid, railway station, regenerative braking integration, power flow, MPC.
\end{abstract}

\section{INTRODUCTION}

Distributed power generation utilizing renewable energy source such as solar, wind, fuel cell, and biomass can help to alleviate the pressure of energy shortage and to reduce environment pollution. Direct Current (DC) microgrids are attracting interest for their ability to easily integrate modern loads, renewable sources and energy storage [1], and transportation systems is one of the interested domains [2], [3], [4], [5]. In this paper a Smart Railway Station is considered, where the energy utilization is more efficient compared to a normal railway station thanks to the presence of solar energy, recovery braking systems and storage devices to supply the local loads. A dedicated DC microgrid is treated, where the regeneration of the train braking energy is seen either as an important possibility to recycle electric power, due to the fact that it is naturally available when the train uses electric brakes to slow down its engines instead of using mechanical brakes, but either as a problem for voltage stability and power quality, due to its intermittent high peaks of power. Therefore, a dedicated power management controller able to provide optimal reference values to the local controllers of the devices composing the DC microgrid is needed, to reach the target to recycling the train braking energy in a railway station while assuring its power flow and keeping voltage inside operation bounds.

The purpose of this work is to introduce a dedicated power management model for a Smart Railway Station able to store the regenerated energy in a battery using a supercapacitor as energy buffer while keeping a correct power balance among

Zeqin Sheng, Alessio Iovine and Lilia Galai-Dol are with Efficacity, R\&D Institute for Urban Energy Transition, Paris, France.

Alessio Iovine is also with the Center of Excellence DEWS, Department of Information Engineering, Computer Science and Mathematics, University of L'Aquila, Italy.

Gilney Damm is with IBISC Laboratory, Universite dEvry-Val dEssonne, 40 rue du Pelvoux, 91020 Evry, France. E-mail: zeqin.sheng@supelec.fr, alessio.iovine@ieee.org, gilney.damm@ibisc.fr, 1.galai-dol@efficacity.com. The research leading to these results has received funding from the Italian Government under Cipe resolution n.135 (Dec. 21, 2012), project INnovating City Planning through Information and Communication Technologies (INCIPICT)

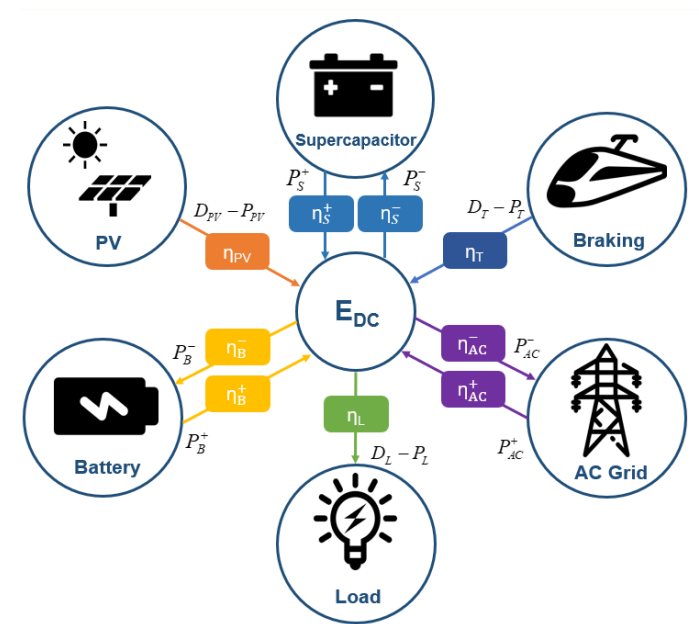

Fig. 1. The considered framework in a power flow scheme the two renewables, the storages, the Alternate Current (AC) main grid in the train station and the local loads, as depicted in Fig. 1. In recent years, a lot of research has been carried out in terms of control strategies for optimal management of the regenerative energy in microgrids [6], [7], [8], [9], but there are still not yet contributions on power management models dedicated to DC microgrids with different kind of Energy Storage Systems (ESS).

The control target of the proposed power management model is to provide the needed references to the low level controllers that are dedicated to each physical device in the microgrid [10], [11], considering given references and constraints for the battery energy and the power demanded and provided to the $\mathrm{AC}$ grid. Only the power management control level is treated in this work [12], [13]: the lower [14], [15], [16] and higher [6], [17] control levels are supposed to work properly and to meet their targets. This paper extends the preliminary results described in [18], considering power losses and converter efficiency, and is focusing on a specific application as the Smart Railway Station. The resulting problem is a non linear optimization one, and it is solved by a Model Predictive Control (MPC) formulation for Mixed Integer Quadratic Programming (MIQP) [19], [17], [20].

This paper is organized as follows. In Section II the power management model is introduced. Then in Section III the adopted algorithm using MPC is carried out. Section IV provides simulation results and compares different cases, while in Section V conclusions are outlined.

\section{Power Management Model}

\section{A. Energy Equations}

Fig. 1 describes the considered microgrid and its power flow. According to it, the stored energies into the DC micro- 
grid, the battery and the supercapacitor will vary depending on the interaction of $\mathrm{PV}$, regenerative braking, AC grid and load. Indeed, the energy variations in the battery and the supercapacitor depend on the power output of these devices, while for the DC they depend on the power balance between the produced and demanded power [18], [21].

$E_{D C}, E_{B}, E_{S}$ are the energies stored in the DC microgrid, battery and supercapacitor, respectively. $D_{P V}-P_{P V}$ is the power produced by the PV array, where $D_{P V}$ is the current available power and $P_{P V}$ is the calculated quantity to be neglected for stability purposes. With similar configuration, $D_{T}-P_{T}$ is the power produced by the train braking, where $D_{T}$ is the current available power and $P_{T}$ is the neglected one, and $D_{L}-P_{L}$ is the power demanded by the load, with $D_{L}$ the current demanded power and $P_{L}$ the quantity to be disconnected to ensure effective feasibility of the optimization problem (load shedding).

$P_{B}^{+}, P_{B}^{-}, P_{S}^{+}, P_{S}^{-}, P_{A C}^{+}, P_{A C}^{-}$are the powers exchanged by the battery ,the supercapacitor and the AC grid, respectively, where $P_{B}^{+}, P_{S}^{+}, P_{A C}^{+}$are the provided powers and $P_{B}^{-}$, $P_{S}^{-}, P_{A C}^{-}$are the absorbed ones. The parameters $\eta_{P V}, 1 / \eta_{L}$, $\eta_{B}^{+}, 1 / \eta_{B}^{-}, \eta_{S}^{+}, 1 / \eta_{P V}^{-}, \eta_{T}, \eta_{A C}^{+}$and $1 / \eta_{A C}^{-}$describe the loss in efficiency during the power flow. A parameter $\alpha_{S}$ allows us to consider the self-discharge ratio of the supercapacitor taking place in the considered time interval $T$; the small self-discharge ratio of the battery is neglected because of the relative short time span considered with respect to the battery dynamics. The dynamical system resulting from Fig. 1 is then:

$\left\{\begin{array}{l}E_{D C}(k+1)=E_{D C}(k)-T\left[\frac{1}{\eta_{L}}\left(D_{L}(k)-P_{L}(k)\right)\right]+ \\ +T\left[\eta_{P V}\left(D_{P V}(k)-P_{P V}(k)\right)+\eta_{B}^{+} P_{B}^{+}(k)\right]+ \\ +T\left[-\frac{1}{\eta_{B}^{-}} P_{B}^{-}(k)+\eta_{S}^{+} P_{S}^{+}(k)-\frac{1}{\eta_{S}^{-}} P_{S}^{-}(k)\right]+ \\ +T\left[\eta_{T}\left(D_{T}(k)-P_{T}(k)\right)+\eta_{A C}^{+} P_{A C}^{+}(k)-\frac{1}{\eta_{A C}^{-}} P_{A C}^{-}(k)\right] \\ E_{B}(k+1)=E_{B}(k)+T\left[P_{B}^{-}(k)-P_{B}^{+}(k)\right] \\ E_{S}(k+1)=\left(1-T \alpha_{S}\right) E_{S}(k)+T\left[P_{S}^{-}(k)-P_{S}^{+}(k)\right]\end{array}\right.$

which can be rewritten in a linear discrete-time form as

$$
x(k+1)=A x(k)+B u(k)+D d(k)
$$

where the state is

$$
x=\left[\begin{array}{lll}
E_{D C} & E_{B} & E_{S}
\end{array}\right]^{T}=\left[\begin{array}{lll}
x_{1} & x_{2} & x_{3}
\end{array}\right]^{T}
$$

and the control input and disturbance vector are

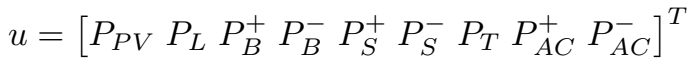

$$
\begin{aligned}
& =\left[\begin{array}{lllllllll}
u_{1} & u_{2} & u_{3} & u_{4} & u_{5} & u_{6} & u_{7} & u_{8} & u_{9}
\end{array}\right]^{T} \\
& d=\left[\begin{array}{lll}
D_{P V} & D_{L} & D_{T}
\end{array}\right]^{T}=\left[\begin{array}{lll}
d_{1} & d_{2} & d_{3}
\end{array}\right]^{T} .
\end{aligned}
$$

The discrete time matrices $\mathrm{A}, \mathrm{B}, \mathrm{D}$ are

$$
\begin{gathered}
A=\left[\begin{array}{ccc}
1 & 0 & 0 \\
0 & 1 & 0 \\
0 & 0 & 1-T \alpha_{S}
\end{array}\right] \quad D=\left[\begin{array}{ccc}
\eta_{P V} & -\frac{1}{\eta_{L}} & \eta_{T} \\
0 & 0 & 0 \\
0 & 0 & 0
\end{array}\right] \\
B=\left[\begin{array}{ll}
B_{1} & B_{2}
\end{array}\right]
\end{gathered}
$$

$$
\begin{gathered}
B_{1}=\left[\begin{array}{cccc}
-\eta_{P V} & \frac{1}{\eta_{L}} & \eta_{B} & -\frac{1}{\eta_{B}} \\
0 & 0 & -1 & 1 \\
0 & 0 & 0 & 0
\end{array}\right] \\
B_{2}=\left[\begin{array}{ccccc}
\eta_{S} & -\frac{1}{\eta_{S}} & -\eta_{T} & \eta_{A C} & -\frac{1}{\eta_{A C}} \\
0 & 0 & 0 & 0 & 0 \\
-1 & 1 & 0 & 0 & 0
\end{array}\right]
\end{gathered}
$$

\section{B. Constrains}

The system introduced in (1) must consider physical and control-related constraints for the devices, here introduced:

1) DC grid: To ensure the power quality and to avoid problems related to the connection with the physical devices, the energy stored in the DC grid must be kept between an interval, i.e.

$$
E_{D C}^{m} \leq E_{D C}(k) \leq E_{D C}^{M}, \forall k
$$

where $E_{D C}^{m}, E_{D C}^{M}>0$.

2) Battery: To protect the devices, the energy in the battery should remain in a range of values, i.e.

$$
E_{B}^{m} \leq E_{B}(k) \leq E_{B}^{M}, \forall k
$$

where $E_{B}^{m}, E_{B}^{M}>0$. The power absorbed/provided by the battery is also bounded:

$$
\begin{aligned}
& 0 \leq P_{B}^{+}(k) \leq \bar{P}_{B}^{+}, \forall k \\
& 0 \leq P_{B}^{-}(k) \leq \bar{P}_{B}^{-}, \forall k
\end{aligned}
$$

where $\bar{P}_{B}^{+}, \bar{P}_{B}^{-}>0$. As the life time of the battery is very important, strong constraints on battery power variation are imposed:

$$
\begin{aligned}
& \left\|P_{B}^{+}(k+1)-P_{B}^{+}(k)\right\| \leq \Delta \bar{P}_{B}^{+}, \forall k \\
& \left\|P_{B}^{-}(k+1)-P_{B}^{-}(k)\right\| \leq \Delta \bar{P}_{B}^{-}, \forall k
\end{aligned}
$$

where $\Delta \bar{P}_{B}^{+}, \Delta \bar{P}_{B}^{-}>0$. Since the power coming in or out the battery cannot take place at the same time, another constraint is implemented:

$$
P_{B}^{+}(k) \times P_{B}^{-}(k)=0, \forall k
$$

This constraint, which avoids simultaneous battery charging and discharging, is described using the binary variable $S_{B}$ :

$$
\begin{aligned}
& S_{B}(k) \in\{0,1\}, \forall k \\
& 0 \leq P_{B}^{+}(k) \leq S_{B}(k) \cdot \bar{P}_{B}^{+}, \forall k \\
& 0 \leq P_{B}^{-}(k) \leq\left(1-S_{B}(k)\right) \cdot \bar{P}_{B}^{-}, \forall k
\end{aligned}
$$

Due to this formulation, the linear control problem becomes nonlinear and the MIQP is necessary.

3) Supercapacitor: The constraints for the supercapacitor are nearly the same as for the battery, but the power variations are not bounded since the supercapacitor has to ensure the voltage stability with respect to the variations taking place on the grid. The energy in the supercapacitor is bounded by

$$
E_{S}^{m} \leq E_{S}(k) \leq E_{S}^{M}, \forall k
$$


where $E_{S}^{m}, E_{S}^{M}>0$. The power absorbed/provided by the supercapacitor is bounded as well, for physical reasons:

$$
\begin{aligned}
& 0 \leq P_{S}^{+}(k) \leq \bar{P}_{S}^{+}, \forall k \\
& 0 \leq P_{S}^{-}(k) \leq \bar{P}_{S}^{-}, \forall k
\end{aligned}
$$

where $\bar{P}_{S}^{+}, \bar{P}_{S}^{-}>0$. As for the battery, the charging and discharging phenomena of the supercapacitor cannot take place simultaneously, and the $S_{S}$ binary variable is used to impose it:

$$
\begin{aligned}
& S_{S}(k) \in\{0,1\}, \forall k \\
& 0 \leq P_{S}^{+}(k) \leq S_{S}(k) \cdot \bar{P}_{S}^{+}, \forall k \\
& 0 \leq P_{S}^{-}(k) \leq\left(1-S_{S}(k)\right) \cdot \bar{P}_{S}^{-}, \forall k
\end{aligned}
$$

4) AC Grid: The AC grid represents an added degree of freedom and is seen as a source or a load depending on the needs of the DC microgrid: it is then possible to provide power to it according to the availability of power from renewables and battery or to absorb it in case of necessity. Obviously, the possibility to use it as buffer is reduced by economic reasons not treated here but considered by the higher level controller when providing the battery energy reference. The constraints are only on the maximum power to be exchanged and on the power variations:

$$
\begin{aligned}
& \left\|P_{A C}^{+}(k+1)-P_{A C}^{+}(k)\right\| \leq \Delta \bar{P}_{A C}^{+}, \forall k \\
& \left\|P_{A C}^{-}(k+1)-P_{A C}^{-}(k)\right\| \leq \Delta \bar{P}_{A C}^{-}, \forall k
\end{aligned}
$$

where $\Delta \bar{P}_{A C}^{+}, \Delta \bar{P}_{A C}^{-}>0$. As for battery and supercapacitor, the power flow is bounded:

$$
\begin{aligned}
& S_{A C}(k) \in\{0,1\}, \forall k \\
& 0 \leq P_{A C}^{+}(k) \leq S_{A C}(k) \cdot \bar{P}_{A C}^{+}, \forall k \\
& 0 \leq P_{A C}^{-}(k) \leq\left(1-S_{A C}(k)\right) \cdot \bar{P}_{A C}^{-}, \forall k
\end{aligned}
$$

with $\bar{P}_{A C}^{+}, \bar{P}_{A C}^{-}>0$.

5) $\underline{P V}$ : The power from the PV array cannot be negative:

$$
D_{P V}(k)-P_{P V}(k) \geq 0, \forall k
$$

where $P_{P V}(k) \geq 0, \forall k$.

6) Load: The power consumed by the load is bounded to be positive:

$$
D_{L}(k)-P_{L}(k) \geq 0, \forall k
$$

where $P_{L}(k) \geq 0, \forall k$.

7) Train braking: As for the constraint of the PV, the power provided by the train braking cannot be negative:

$$
D_{T}(k)-P_{T}(k) \geq 0, \forall k
$$

where $P_{T}(k) \geq 0, \forall k$.

\section{Power Management Controller}

According to the model and the constraints introduced Sections II-A and II-B, it is now possible to define the optimal control problem. As already mentioned, it will result in a MIQP problem and will be solved using the MPC [19].

For problem feasibility reasons, the hypothesis of knowing the disturbances $D_{L}(k), D_{P V}(k)$ and $D_{T}(k)$ for $k, k+$
$1, \ldots, k+N$, where $N$ is the considered prediction horizon, must be done. While it introduces small prediction errors for $D_{L}(k)$ and $D_{P V}(k)$, as described in [18], it matches the reality for $D_{T}(k)$, since its evolution is known. If future load variations are known, as loads are often scheduled or periodic, this information can be included in the algorithm.

The target of the power management controller is to compute the power optimal set points values for the lower level controllers to ensure power balance and a desired level of charge for the ESSs. Desired energy levels for DC grid $E_{D C}^{r}=x_{1}^{r}$, battery $E_{B}^{r}=x_{2}^{r}$ and supercapacitor $E_{S}^{r}=x_{3}^{r}$ are considered, which are computed by the higher control level (see [16], [10]). The reference vector for the state is

$$
x^{r}=\left[\begin{array}{lll}
x_{1}^{r} & x_{2}^{r} & x_{3}^{r}
\end{array}\right]^{T}=\left[\begin{array}{lll}
E_{D C}^{r} & E_{B}^{r} & E_{S}^{r}
\end{array}\right]^{T} .
$$

\section{A. Optimal Control Problem}

The selected cost function has the objective to bring the state as close as possible to the reference vector while satisfying the introduced constraints. Once the initial state $x_{0}(k)$ and the prediction horizon $N$ are given, the problem $O$ is solved at each step $k$ by the MPC strategy.

$$
\begin{aligned}
& O=\min _{u(\cdot)} \frac{1}{2} \tilde{x}(k+N)^{T} P \tilde{x}(k+N)+ \\
& +\frac{1}{2} \sum_{i=k}^{k+N-1}\left[\tilde{x}(i)^{T} Q \tilde{x}(i)+u(i)^{T} R u(i)\right] \\
& \text { s.t. } \\
& \tilde{x}(i)=x(i)-x^{r}, \forall i \\
& x(i+1)=A x(i)+B u(i)+D d(i), \forall i \\
& x(k)=x_{0}(k) \text {, } \\
& x_{1}^{m} \leq x_{1}(i) \leq x_{1}^{M}, \forall i \\
& x_{2}^{m} \leq x_{2}(i) \leq x_{2}^{M}, \forall i \\
& x_{3}^{m} \leq x_{3}(i) \leq x_{3}^{M}, \forall i \\
& S_{B}(i), S_{S}(i), S_{A C}(i) \in\{0,1\}, \forall i \\
& 0 \leq u_{1}(i) \leq d_{1}(i), \forall i \\
& 0 \leq u_{2}(i) \leq d_{2}(i), \forall i \\
& 0 \leq u_{3}(i) \leq S_{B}(k) \cdot \bar{P}_{B}^{+}, \forall i \\
& 0 \leq u_{4}(i) \leq\left(1-S_{B}(k)\right) \cdot \bar{P}_{B}^{-}, \forall i \\
& 0 \leq u_{5}(i) \leq S_{S}(k) \cdot \bar{P}_{S}^{+}, \forall i \\
& 0 \leq u_{6}(i) \leq\left(1-S_{S}(k)\right) \cdot \bar{P}_{S}^{-}, \forall i \\
& 0 \leq u_{7}(i) \leq d_{3}(i), \forall i \\
& 0 \leq u_{8}(i) \leq S_{A C}(k) \cdot \bar{P}_{A C}^{+}, \forall i \\
& 0 \leq u_{9}(i) \leq\left(1-S_{A C}(k)\right) \cdot \bar{P}_{A C}^{-}, \forall i \\
& \left\|u_{3}(i+1)-u_{3}(i)\right\| \leq \Delta \bar{P}_{B}^{+}, \forall i \\
& \left\|u_{4}(i+1)-u_{4}(i)\right\| \leq \Delta \bar{P}_{B}^{-}, \forall i \\
& \left\|u_{8}(i+1)-u_{8}(i)\right\| \leq \Delta \bar{P}_{A C}^{+}, \forall i \\
& \left\|u_{9}(i+1)-u_{9}(i)\right\| \leq \Delta \bar{P}_{A C}^{-}, \forall i
\end{aligned}
$$

where $P>0, Q>0, R>0$ are weight matrices. 
TABLE I

REFERENCES

\begin{tabular}{|c|c|c|}
\hline$E_{D C}^{r}$ & $E_{B}^{r}$ & $E_{S}^{r}$ \\
\hline $1.39 e^{-5} \mathrm{kWh}$ & $270 \mathrm{kWh}$ & $5 \mathrm{kWh}$ \\
\hline
\end{tabular}

TABLE II

CONSTRAINTS FOR THE STATE VARIABLES

\begin{tabular}{|c|c|c|c|c|c|}
\hline$E_{D C}^{m}$ & $90 \% E_{D C}^{r}$ & $E_{B}^{m}$ & $90 \mathrm{kWh}$ & $E_{S}^{m}$ & $1.41 \mathrm{kWh}$ \\
\hline$E_{D C}^{M}$ & $110 \% E_{D C}^{r}$ & $E_{B}^{M}$ & $270 \mathrm{kWh}$ & $E_{S}^{M}$ & $8 \mathrm{kWh}$ \\
\hline
\end{tabular}

\section{Simulations}

Simulations of the proposed power management controller applied to the microgrid in Fig. 1 are introduced in this Section. They are obtained using Matlab R2017b with the toolbox Yalmip [22].

Simulation time is 170 seconds, while the sampling time is one second and the prediction horizon is 10 time steps, both for state variables and control inputs. As already mentioned, the MPC method requires a forecast for the future disturbances over the rolling prediction horizon. In this simulation, for each prediction horizon, the future disturbance related to the train braking is given, while future solar power and demanded load are considered constant with respect to the last measured value. Real data are used for solar power production and regenerative braking. Used references and constraints are introduced in Tables I,II,III,IV. Note that the $P_{\Omega}^{+}$and $P_{\Omega}^{-}$are merged into $P_{\Omega}, \Omega=\{B, S, A C\}$, for simplicity reasons in the following: for battery and supercapacitor, positive and negative values mean to provide and absorb power to the DC microgrid respectively; for the $\mathrm{AC}$ grid, positive and negative values mean to demand and supply power to the AC grid respectively.

Two case studies will be introduced and discussed, in order to show the different results that can be obtained when considering the same situation with different constraints for the battery. Both case studies describe a situation where initially the supercapacitor has the energy lower than its reference, two train braking events take place in the simulation (each lasts 12 seconds, see Fig. 8 and 9) and the DC microgrid continuously provides at least $200 \mathrm{~kW}$ and at most $300 \mathrm{~kW}$ to the AC grid (see Fig. 10 and 11). For Case study 1 the maximum power absorbed/provided by the battery is

TABLE III

CONSTRAINTS FOR THE CONTROL INPUTS

\begin{tabular}{|c|c|c|c|}
\hline $\bar{P}_{B}^{+}$ & $240 \mathrm{kWh}$ (case 1) & $\bar{P}_{B}^{-}$ & $240 \mathrm{kWh}$ (case 1) \\
\hline $\bar{P}_{B}^{+}$ & $360 \mathrm{kWh}$ (case 2) & $\bar{P}_{B}^{-}$ & $360 \mathrm{kWh}$ (case 2) \\
\hline $\bar{P}_{S}^{+}$ & $1000 \mathrm{kWh}$ & $\bar{P}_{S}^{-}$ & $1000 \mathrm{kWh}$ \\
\hline $\bar{P}_{A C}^{+}$ & $300 \mathrm{kWh}$ & $\bar{P}_{A C}^{-}$ & $300 \mathrm{kWh}$ \\
\hline$\Delta \bar{P}_{B}^{+}$ & $20 \mathrm{kWh}$ & $\Delta \bar{P}_{B}^{-}$ & $20 \mathrm{kWh}$ \\
\hline$\Delta \bar{P}_{A C}^{+}$ & $100 \mathrm{kWh}$ & $\Delta \bar{P}_{A C}^{-}$ & $100 \mathrm{kWh}$ \\
\hline
\end{tabular}

TABLE IV

PARAMETERS OF THE DYNAMICAL MODEL

\begin{tabular}{|c|c|c|c|c|c|c|c|}
\hline$\eta_{B}^{+} / \eta_{B}^{-}$ & 0.93 & $\eta_{S}^{+} / \eta_{S}^{-}$ & 0.97 & $\eta_{P V}$ & 1 & $\eta_{L}$ & 1 \\
\hline$\eta_{A C}^{+} / \eta_{A C}^{-}$ & 0.95 & $\alpha_{S}$ & $10^{-3}$ & $\eta_{T}$ & 1 & $T$ & $1 \mathrm{~s}$ \\
\hline
\end{tabular}

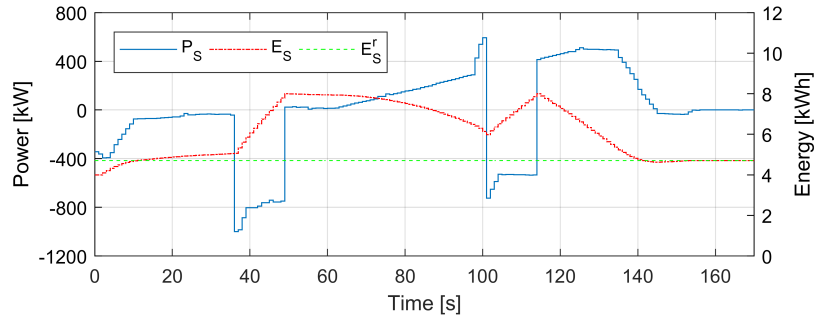

Fig. 2. Case 1 - The energy of the supercapacitor $E_{S}$ (red line with right ordinate) with respect to its reference(green line) and the calculated optimal value of $P_{S}\left(P_{S}^{+}\right.$and $\left.P_{S}^{-}\right)$(blue line with left ordinate).

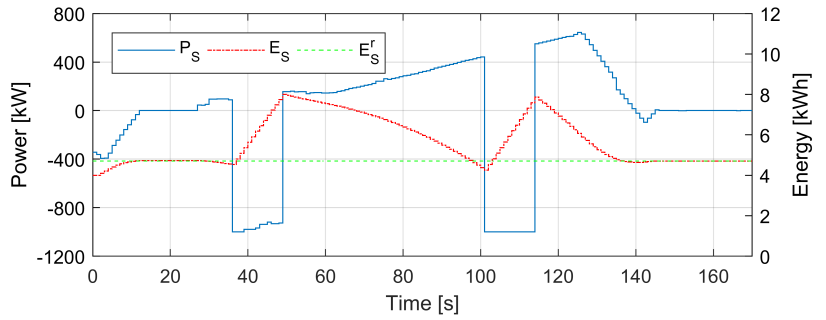

Fig. 3. Case 2 - The energy of the supercapacitor $E_{S}$ (red line with right ordinate) with respect to its reference(green line) and the calculated optimal value of $P_{S}\left(P_{S}^{+}\right.$and $\left.P_{S}^{-}\right)$(blue line with left ordinate).

240kW, while Case study 2 has more relaxed constraints for the battery power with a maximum of $360 \mathrm{~kW}$. It is worth noticing that if there is more power absorbed/provided by the battery, the battery lifetime will reduce. The considered solar and load power conditions are equal, as it is possible to see from Fig. 6, 7, 12 and 13.

Fig. 2, 3, 4 and 5 show that the proposed power management scheme reaches the target to properly control the energies in the battery and the supercapacitor with respect to their desired references. Indeed, when the train braking recovery phenomena takes place, the supercapacitor absorbs the high amount of power coming from the train to keep the power balance. As there is much more power arriving,

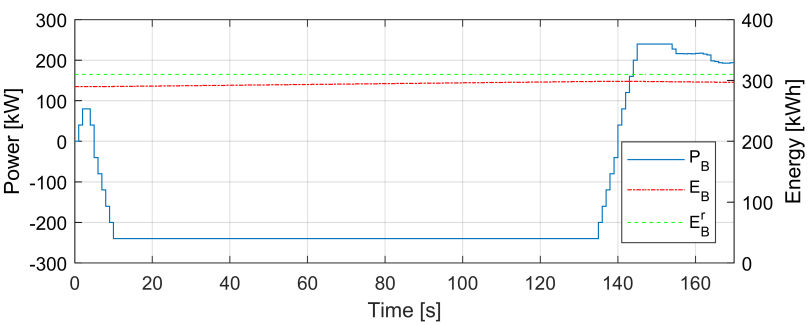

Fig. 4. Case 1 - The energy of the battery $E_{B}$ (red line with the right ordinate) with respect to its reference(green line) and the calculated optimal value of $P_{B}\left(P_{B}^{+}\right.$and $\left.P_{B}^{-}\right)$(blue line with left ordinate).

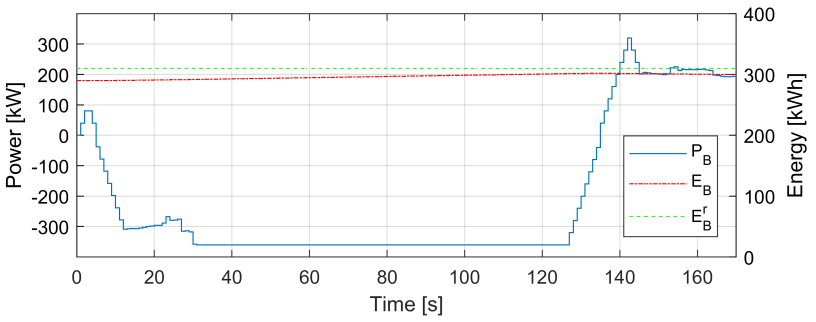

Fig. 5. Case 2 - The energy of the battery $E_{B}$ (red line with the right ordinate) with respect to its reference(green line) and the calculated optimal value of $P_{B}\left(P_{B}^{+}\right.$and $\left.P_{B}^{-}\right)$(blue line with left ordinate). 


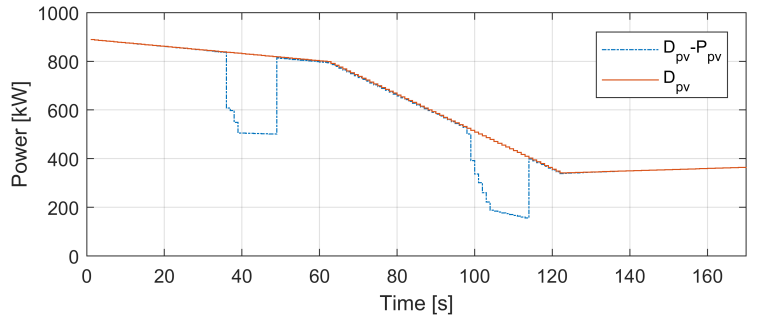

Fig. 6. Case 1 - The available power $D_{P V}$ (red line) from the renewables and the calculated optimal value of $D_{P V}-P_{P V}$ (blue line).

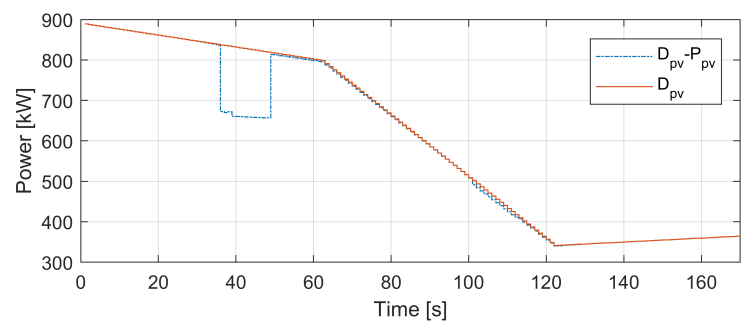

Fig. 7. Case 2 - The available power $D_{P V}$ (red line) from the renewables and the calculated optimal value of $D_{P V}-P_{P V}$ (blue line).

the available power from renewables is partially neglected. After the recovery phenomena, the supercapacitor starts to provide back the power to the DC grid and slowly return to its reference (see Fig. 2 and 3). It is worth noticing that after the first train braking event the energy of supercapacitor is released in a slower manner with respect to the second train braking event. This is due to decrease of the PV available power, which allows for a faster discharge. Moreover, due to the hidden choice to not use power from the $\mathrm{AC}$ grid for economical reasons, we observe that there is no power provided by the AC grid: the energy reference for the battery has taken that into account.

The comparison between the two considered cases shows how the more relaxed constraints impact on the system evolution and on its performances. Indeed, as easily predictable, the capability of the system to store renewable power increases with the increase of the possibility to store renewable power in the battery, as can be seen from the differences in the neglected available powers from PV and train recovery systems in Fig. 6, 7, 8 and 9. Moreover, a faster convergence rate to the references is available for the energies in the battery (see Fig.4 and 5), clearly, and the supercapacitor as well, as depicted in Fig. 2 and 3. As the battery is able to absorb more power, the level of energy in the supercapacitor returns faster to its desired value.

Compared to the Case study 1, in Case study 2 the battery provides power earlier as there is not enough power from

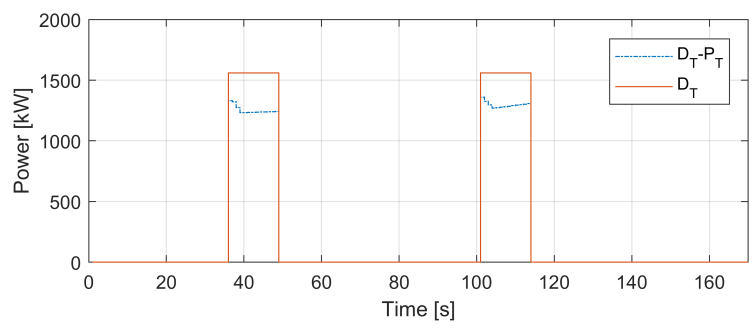

Fig. 8. Case 1 - The available power $D_{T}$ (red line) from the train braking and the calculated optimal value of $D_{T}-P_{T}$ (blue line).

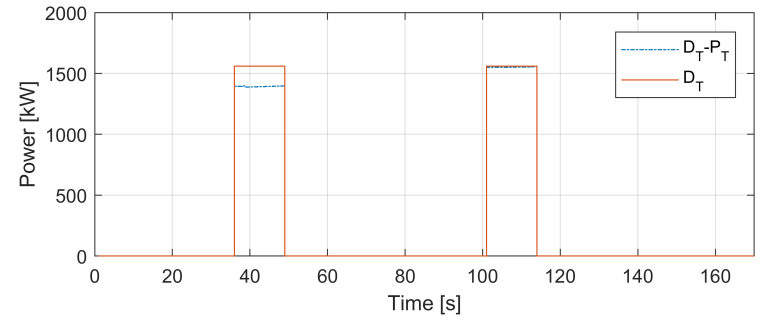

Fig. 9. Case 2 - The available power $D_{T}$ (red line) from the train braking and the calculated optimal value of $D_{T}-P_{T}$ (blue line).

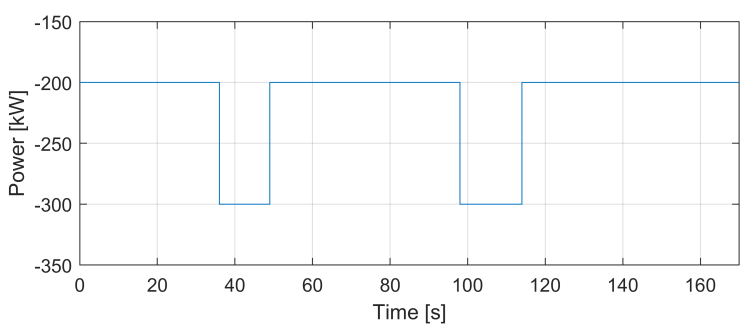

Fig. 10. Case 1 - The calculated optimal value of $P_{A C}\left(P_{A C}^{+}\right.$and $\left.P_{A C}^{-}\right)$

the renewables and it will help the energy of supercapacitor to return to its reference. As the power limit of battery is changed, the DC microgrid supply less power to the AC grid during the second train braking. For this microgrid to be autonomous in energy, in Fig.12 the necessity to partially shut down the load of a small value is highlighted over the time range of [135s-150s]. As a final verification, Fig.14 and Fig.15 confirm DC microgrid stability with respect to its constraints in both cases.

\section{CONCLUSIONS}

In this paper, a dynamic power management controller of an AC-connected DC microgrid integrated in a Smart Railway Station is introduced. While receiving energy references for the storages by a higher control level, the proposed optimal control strategy targets to obtain the power set point references to be implemented by the physical devices at a
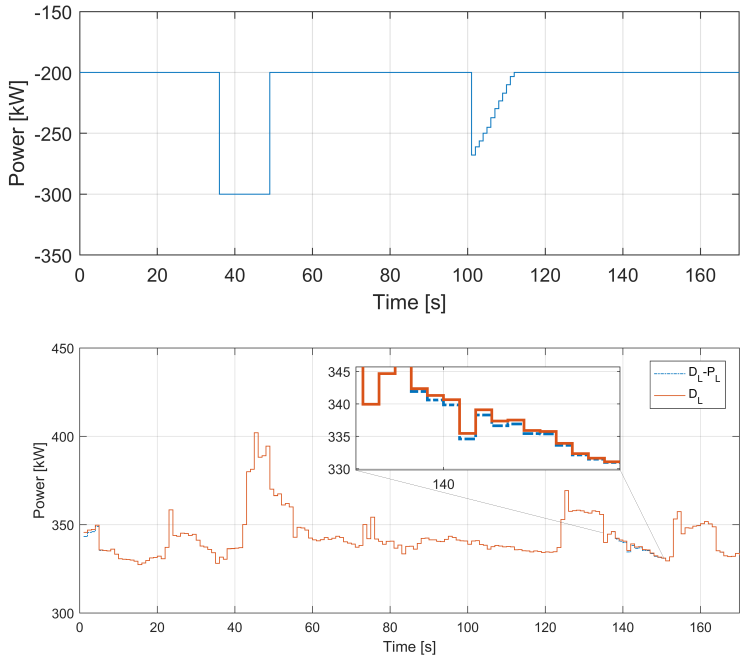

Fig. 12. Case 1 - The real power demanded by the load $D_{L}$ (red line) and the calculated optimal value of $D_{L}-P_{L}$ (blue line) 


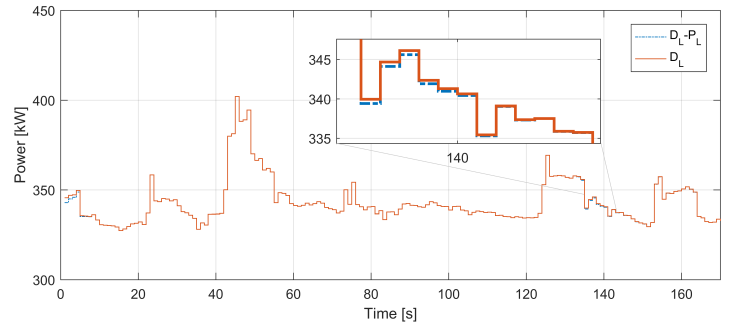

Fig. 13. Case 2 - The real power demanded by the load $D_{L}$ (red line) and the calculated optimal value of $D_{L}-P_{L}$ (blue line)

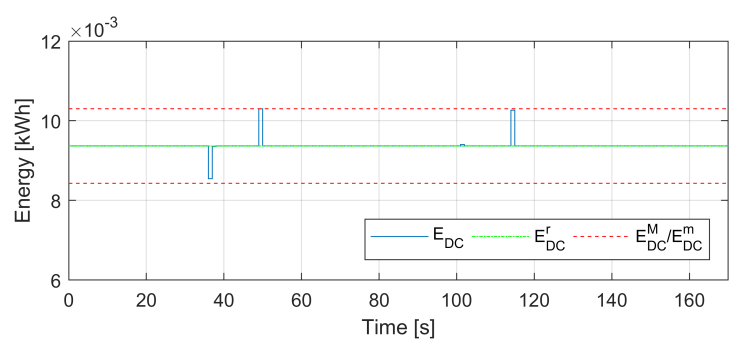

Fig. 14. Case 1 - The DC grid energy (blue line) with respect to its reference (green line) and the limits (red line)

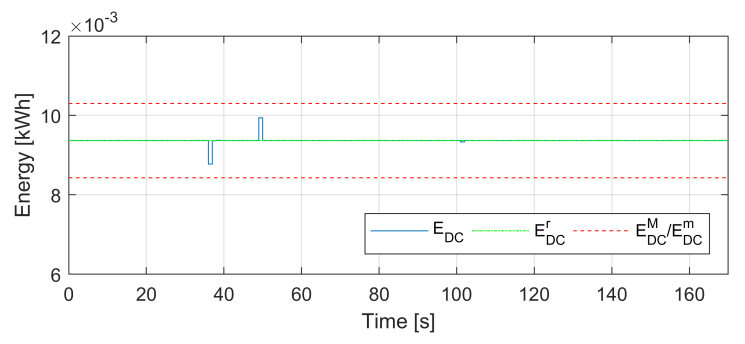

Fig. 15. Case 2 - The DC grid energy (blue line) with respect to its reference (green line) and the limits (red line)

lower control level to the purpose to preserve voltage and power stability in the DC microgrid. The MPC method with the receding horizon technique is utilized.

The considered cases show the good capability of the system to manage the complex task of recovering the energy from the train braking while ensuring power balance and a proper energy level in the storage devices. The proposed simulations clearly depict the importance to correctly find a proper trade-off between the control-induced constraints and the physical ones, correctly sizing the components and weighting the relations among them.

The proper sizing of the storage devices and their physical constraints was out of the scope of this work. Nevertheless, future works can focus on such aspects. Indeed, with the proposed controller, it would be possible to study and optimize the needed size of the components looking for the best tradeoff among system performances and economical constraints (as battery lifetime or supercapacitor sizing, for example).

\section{REFERENCES}

[1] L. E. Zubieta, "Are Microgrids the Future of Energy?: DC Microgrids from Concept to Demonstration to Deployment," IEEE Electrification Magazine, vol. 4, no. 2, pp. 37-44, June 2016.

[2] L. Galaï-Dol, A. De Bernardinis, A. Nassiopoulos, A. Peny, and F. Bourquin, "On the use of train braking energy regarding the electrical consumption optimization in railway station," Transportation Research Procedia, vol. 14, pp. 655-664, 2016.
[3] A. Verdicchio, P. Ladoux, H. Caron, and C. Courtois, "New MediumVoltage DC Railway Electrification System," IEEE Transactions on Transportation Electrification, vol. 4, no. 2, pp. 591-604, June 2018.

[4] R. R. Pecharromán, A. López-López, A. P. Cucala, and A. FernándezCardador, "Riding the Rails to DC Power Efficiency: Energy efficiency in dc-electrified metropolitan railways." IEEE Electrification Magazine, vol. 2, no. 3, pp. 32-38, Sept 2014.

[5] L. Galaï-Dol and A. de Bernardinis, "AC or DC grid for railway stations?" in PCIM Europe 2016; International Exhibition and Conference for Power Electronics, Intelligent Motion, Renewable Energy and Energy Management, May 2016, pp. 1-8.

[6] D. Roch-Dupré, Âlvaro J. López-López, R. R. Pecharromán, A. P. Cucala, and A. Fernández-Cardador, "Analysis of the demand charge in dc railway systems and reduction of its economic impact with energy storage systems," International Journal of Electrical Power and Energy Systems, vol. 93, pp. 459 - 467, 2017.

[7] A. Gonzlez-Gil, R. Palacin, and P. Batty, "Sustainable urban rail systems: Strategies and technologies for optimal management of regenerative braking energy," Energy Conversion and Management, vol. 75 , pp. $374-388,2013$.

[8] S. Lu, P. Weston, S. Hillmansen, H. B. Gooi, and C. Roberts, "Increasing the regenerative braking energy for railway vehicles," IEEE Trans. on Intelligent Transportation Systems, vol. 15, no. 6, pp. 2506-2515, Dec 2014.

[9] J. A. Aguado, A. J. S. Racero, and S. de la Torre, "Optimal operation of electric railways with renewable energy and electric storage systems," IEEE Trans. on Smart Grid, vol. 9, no. 2, pp. 993-1001, March 2018.

[10] L. Meng, Q. Shafiee, G. F. Trecate, H. Karimi, D. Fulwani, X. Lu, and J. M. Guerrero, "Review on Control of DC Microgrids and Multiple Microgrid Clusters," IEEE Journal of Emerging and Selected Topics in Power Electronics, vol. 5, no. 3, pp. 928-948, Sept 2017.

[11] T. Dragicevic, X. Lu, J. C. Vasquez, and J. M. Guerrero, "DC MicrogridsPart II: A Review of Power Architectures, Applications, and Standardization Issues," IEEE Transactions on Power Electronics, vol. 31, no. 5, pp. 3528-3549, May 2016.

[12] I. Prodan and E. Zio, "A model predictive control framework for reliable microgrid energy management," International Journal of Electrical Power Energy Systems, vol. 61, pp. 399 - 409, 2014.

[13] E. Jiménez, M. Jiménez Carrizosa, A. Benchaib, G. Damm, and F. Lamnabhi-Lagarrigue, "A new generalized power flow method for multi connected dc grids," International Journal of Electrical Power Energy Systems, vol. 74, pp. 329 - 337, 2016.

[14] A. Iovine, S. B. Siad, G. Damm, E. De Santis, and M. D. Di Benedetto, "Nonlinear Control of a DC MicroGrid for the Integration of Photovoltaic Panels," IEEE Transactions on Automation Science and Engineering, vol. 14, no. 2, pp. 524-535, April 2017.

[15] A. Iovine, M. Jiménez Carrizosa, G. Damm, and P. Alou, "Nonlinear Control for DC MicroGrids enabling Efficient Renewable Power Integration and Ancillary Services for AC grids," IEEE Transactions on Power Systems, pp. 1-1, 2018.

[16] A. Iovine, L. Galai-Dol, E. De Santis, M. D. Di Benedetto, and G. Damm, "Distributed Nonlinear Control for a MicroGrid Embedding Renewables, Train's Energy Recovery System and Storages," in PCIM Europe 2017, May 2017, pp. 1-8.

[17] T. Rigaut, P. Carpentier, J. P. Chancelier, M. De Lara, and J. Waeytens, "Stochastic optimization of braking energy storage and ventilation in a subway station," IEEE Transactions on Power Systems, vol. 34, no. 2, pp. 1256-1263, March 2019.

[18] A. Iovine, G. Damm, E. D. Santis, and M. D. D. Benedetto, "Management controller for a dc microgrid integrating renewables and storages," IFAC-PapersOnLine, vol. 50, no. 1, pp. 90 - 95, 2017, 20th IFAC World Congress.

[19] E. Camacho, C. Bordons, and C. Alba, Model Predictive Control, ser. Advanced Textbooks in Control and Signal Processing. Springer London.

[20] F. Smarra, A. Jain, T. de Rubeis, D. Ambrosini, A. D'Innocenzo, and R. Mangharam, "Data-driven model predictive control using random forests for building energy optimization and climate control," Applied Energy, vol. 226, pp. 1252 - 1272, 2018.

[21] A. Iovine, T. Rigaut, G. Damm, E. De Santis, and M. D. Di Benedetto, "Power Management for a DC MicroGrid integrating Renewables and Storages," Control Engineering Practice, vol. 85, pp. 59 - 79, 2019.

[22] J. Lofberg, "Yalmip : a toolbox for modeling and optimization in matlab," in 2004 IEEE International Conference on Robotics and Automation (IEEE Cat. No.04CH37508), Sept 2004, pp. 284-289. 